Keng E. Choo • Taija K. Nicoli • Lesley J. Bruce •

Michael J. A. Tanner • Andres Ruiz-Linares •

Oliver M. Wrong

\title{
Recessive distal renal tubular acidosis in Sarawak caused by AE1 mutations
}

Received: 17 September 2004 / Revised: 8 July 2005 / Accepted: 13 July 2005 / Published online: 27 October 2005

(C) IPNA 2005

\begin{abstract}
Mutations of the AEl (SLC4A1, Anion-Exchanger 1) gene that codes for band 3 , the renal and red cell anion exchanger, are responsible for many cases of familial distal renal tubular acidosis (dRTA). In Southeast Asia this disease is usually recessive, caused either by homozygosity of a single $A E 1$ mutation or by compound heterozygosity of two different $A E 1$ mutations. We describe two unrelated boys in Sarawak with dRTA associated with compound heterozygosity of $A E 1$ mutations. Both had Southeast Asian ovalocytosis (SAO), a morphological abnormality of red cells caused by a deletion of band 3 residues 400-408. In addition, one boy had a DNA sequence abnormality of band 3 residue (G701D), which has been reported from elsewhere in Southeast Asia. The other boy had the novel sequence abnormality of band $3(\mathrm{Q} 759 \mathrm{H})$ and profound hemolytic anemia.
\end{abstract}

Keywords Band 3 - Distal renal tubular acidosis . Hemolytic anemia $\cdot$ Sarawak

\author{
K. E. Choo \\ Department of Paediatrics and Child Health, \\ Universiti Malaysia Sarawak, \\ Kuching, Sarawak, Malaysia \\ T. K. Nicoli · A. Ruiz-Linares \\ Galton Laboratory, \\ Department of Biology, \\ University College, London, UK \\ L. J. Bruce - M. J. A. Tanner \\ Department of Biochemistry, \\ University of Bristol, \\ Bristol, UK
}

O. M. Wrong

Royal Free and University College London School of Medicine, London, UK

O. M. Wrong $(\bullet)$

Department of Nephrology,

Middlesex Hospital,

Mortimer St., London, W1T 3AA, UK

e-mail: oliverwrong@aol.com

Tel.: +44-20-76374740

\section{Introduction}

Distal renal tubular acidosis (dRTA) commonly presents in childhood with failure to thrive, hypokalemic acidosis, rickets, and nephrocalcinosis. It is often inherited, either as an autosomal dominant or recessive, and when inherited usually results from mutations of the AE1 (SLC4A1) gene on chromosome 17 that codes for band 3, the bicarbonate/ chloride exchanger which is present in both the red cell membrane and the basolateral membrane of the alpha-intercalated cell in the renal collecting duct $[1,2]$. A rarer recessive form of the disease, usually associated with nerve deafness, is caused by mutations affecting the $\mathrm{H}^{+}$-ATPase on the apical membrane of this renal tubular cell $[3,4]$.

Inherited dRTA has not so far been described from Sarawak, a state of eastern Malaysia that occupies much of the northern part of the island of Borneo, but we now report two children in Sarawak with this disease. Both patients had Southeast Asian ovalocytosis (SAO), a morphological red cell abnormality that results from a nine-amino acid deletion of band 3 residues 400-408, and is prevalent in Southeast Asia [5]. SAO by itself does not cause either dRTA or anemia $[5,6,7]$. One of our patients was a mixed race Iban/Chinese child with compound heterozygosity of SAO and a mutation of band 3 residue 701, a combination that has been found in IRTA children in other parts of Southeast Asia [6,7,8]; however, in his case the 701 mutation appeared to be derived from his Chinese father, a race in whom this mutation has not previously been described. The second patient, an Iban child, was a compound heterozygote of SAO with a novel mutation of band 3 residue 759 (band 3 UNIMAS). Both patients had evidence of increased red cell destruction, which in the second child with the SAO/759 mutations amounted to profound hemolytic anemia.

\section{Case reports}

Patient 1, the second of three children of an Iban mother and a father of Chinese ancestry (Fig. 1), had an un- 